\title{
Incidence of acute cholecystitis underwent cholecystectomy in incidence dialysis patients: a nationwide population-based cohort study in Korea
}

\author{
Hanlim Choi ${ }^{1}$, Soon Kil Kwon ${ }^{2}$, Joung-Ho Han ${ }^{2}$, Jun Su Lee ${ }^{2}$, Gilwon Kang ${ }^{3}$, Minseok Kang ${ }^{3}$ \\ ${ }^{1}$ Department of Surgery, Chungbuk National University Hospital, Chungbuk National University College of Medicine, Cheongju, Republic of \\ Korea \\ ${ }^{2}$ Department of Internal Medicine, Chungbuk National University Hospital, Chungbuk National University College of Medicine, Cheongju, \\ Republic of Korea \\ ${ }^{3}$ Department of Health Information and Management, Chungbuk National University College of Medicine, Cheongju, Republic of Korea
}

\begin{abstract}
Background: Patients on dialysis have numerous gastrointestinal problems related to uremia, which may represent concealed cholecystitis. We investigated the incidence and risk of acute cholecystitis in dialysis patients and used national health insurance data to identify acute cholecystitis in Korea.

Methods: The Korean National Health Insurance Database was used, with excerpted data from the insurance claim of the International Classification of Diseases code of dialysis and acute cholecystitis treated with cholecystectomy. We included all patients who commenced dialysis between 2004 and 2013 and selected the same number of controls via propensity score matching.

Results: A total of 59,999 dialysis and control patients were analyzed; of these, 3,940 dialysis patients (6.6\%) and 647 controls (1.1\%) developed acute cholecystitis. The overall incidence of acute cholecystitis was 8.04-fold higher in dialysis patients than in controls (95\% confidence interval, 7.40-8.76). The acute cholecystitis incidence rate (incidence rate ratio, 23.13) was especially high in the oldest group of dialysis patients (aged $\geq 80$ years) compared with that of controls. Dialysis was a significant risk factor for acute cholecystitis (adjusted hazard ratio, 8.94; 95\% confidence interval, 8.19-9.76). Acute cholecystitis developed in 3,558 of 54,103 hemodialysis patients (6.6\%) and in 382 of 5,896 patients $(6.5 \%)$ undergoing peritoneal dialysis.

Conclusion: Patients undergoing dialysis had a higher incidence and risk of acute cholecystitis than the general population. The possibility of a gallbladder disorder developing in patients with gastrointestinal problems should be considered in the dialysis clinic.
\end{abstract}

Keywords: Acute cholecystitis, Epidemiology, Population, Renal dialysis

\section{Introduction}

Acute cholecystitis, an inflammatory gallbladder disorder usually caused by gallstones, is a common gastrointestinal disease in Korea. Despite a good prognosis, it can lead to high morbidity and mortality without proper diagnosis and

Received: December 6, 2020; Revised: June 22, 2021; Accepted: June 28, 2021

Correspondence: Joung-Ho Han

Department of Internal Medicine, Chungbuk National University Hospital, Chungbuk National University College of Medicine, 776, 1sunhwan-ro, Seowon-gu, Cheongju 28644, Republic of Korea. E-mail: joungho@cbnu.ac.kr

ORCID: https://orcid.org/0000-0003-4469-9215

Hanlim Choi and Soon Kil Kwon contributed equally to this work.

Copyright (C) 2022 by The Korean Society of Nephrology

() This is an Open Access article distributed under the terms of the Creative Commons Attribution Non-Commercial and No Derivatives License (http:// creativecommons.org/licenses/by-nc-nd/4.0/) which permits unrestricted non-commercial use, distribution of the material without any modifications, and reproduction in any medium, provided the original works properly cited. 
treatment. The most common symptom is upper abdominal pain, which usually begins in the epigastric region and is then localized to the right upper quadrant. Nausea, vomiting, and fever are generally significant [1]. The prevalence of acute cholecystitis among individuals with abdominal pain is $3 \%$ to $8 \%$, and its incidence is markedly increased after the age of 50 years in the general population [2]. The 30day mortality was $1.1 \%$ in a Japanese-Taiwanese study with similar ethnic characteristics as that of the Korean population [3].

As life expectancy increases, the number of patients with diabetes and hypertension increases globally. The increased number of chronic kidney disease cases correspondingly increases the dialysis population [4], and improved cardiovascular outcomes in the dialysis population result in prolonged dialysis duration and enhanced long-term survival [5]. However, elderly patients demonstrated a relatively decreased survival gain because of multiple medical problems [6]. Therefore, general medical care with superior quality has become important for dialysis patients.

Patients with end-stage renal disease (ESRD) have multiple problems associated with uremia. They have more common nonspecific gastrointestinal problems such as abdominal pain, constipation, dyspepsia, nausea, and irritable bowel syndrome than controls without renal impairment [7]. Although uremia is thought to cause nonspecific gastrointestinal problems, it could mimic specific gastrointestinal illnesses that could result in the misdiagnosis of an important disease. Furthermore, dialysis patients have a higher incidence of gastrointestinal disease than the general population [8]. However, the incidence of acute cholecystitis, its clinical characteristics, and treatment outcomes in dialysis patients are still not fully understood.

This study aimed to determine the incidence and risk of acute cholecystitis in the dialysis population and to investigate the differences among the dialysis modalities in patients with ESRD. We designed a propensity score-matched cohort study using the Korean National Health Insurance Service (KNHIS) data.

\section{Methods}

\section{Database}

Data on patients undergoing dialysis were obtained from the Korean National Health Information database. The KNHIS, a single national insurance provider, covers almost the entire Korean population. This database, which contains reimbursement records from all medical facilities across the country, was used to develop an exposure cohort. We previously reported the incidence of active tuberculosis and cancer in dialysis patients using KNHIS data $[9,10]$.

\section{Definition and selection of cohort}

All incidental patients with ESRD who underwent dialysis for more than 3 months and were diagnosed between 2004 and 2013 in Korea were selected from the database to establish the exposure cohort. The dialysis cohort included patients who claimed insurance for any procedures or services for both hemodialysis and peritoneal dialysis, based on the Korean electronic data interchange codes (O7020, O7021, O9991 for hemodialysis; E6593, O7061, O7062, O7074, O7075, O7080 for peritoneal dialysis) combined with the International Classification of Diseases (ICD) code of chronic kidney disease (N18.**) [10]. Patients who underwent dialysis for more than 3 months were defined by a dialysis code that appeared again within 3 months after the initial dialysis code appeared. In the peritoneal dialysis patient group, codes (O7061 and O7062) were used to find new patients receiving peritoneal dialysis. The date these codes appeared was the first peritoneal dialysis date, and the cases where the peritoneal dialysis code reappeared after 3 months was the peritoneal dialysis patient group.

Patients with a diagnosis of ESRD who were provided with medical services in 2003 and received kidney transplantation were excluded from this cohort to rule out chronic ESRD (Fig. 1).

The control cohort was selected from the KNHIS National Sample Cohort (NSC) from the National Health Information database established by the KNHIS in 2011 [11]. These cohort data covered 1,125,691 Korean individuals and represented $2.2 \%$ of all Korean population disease entities. We excluded patients with dialysis, diagnosed with cholecystitis and/or cholecystectomy, or kidney transplantation (Fig. 1).

\section{Definition of acute cholecystitis and covariables}

The incidence of acute cholecystitis was investigated using ICD 10th Revision (ICD-10) codes. Acute cholecystitis was 


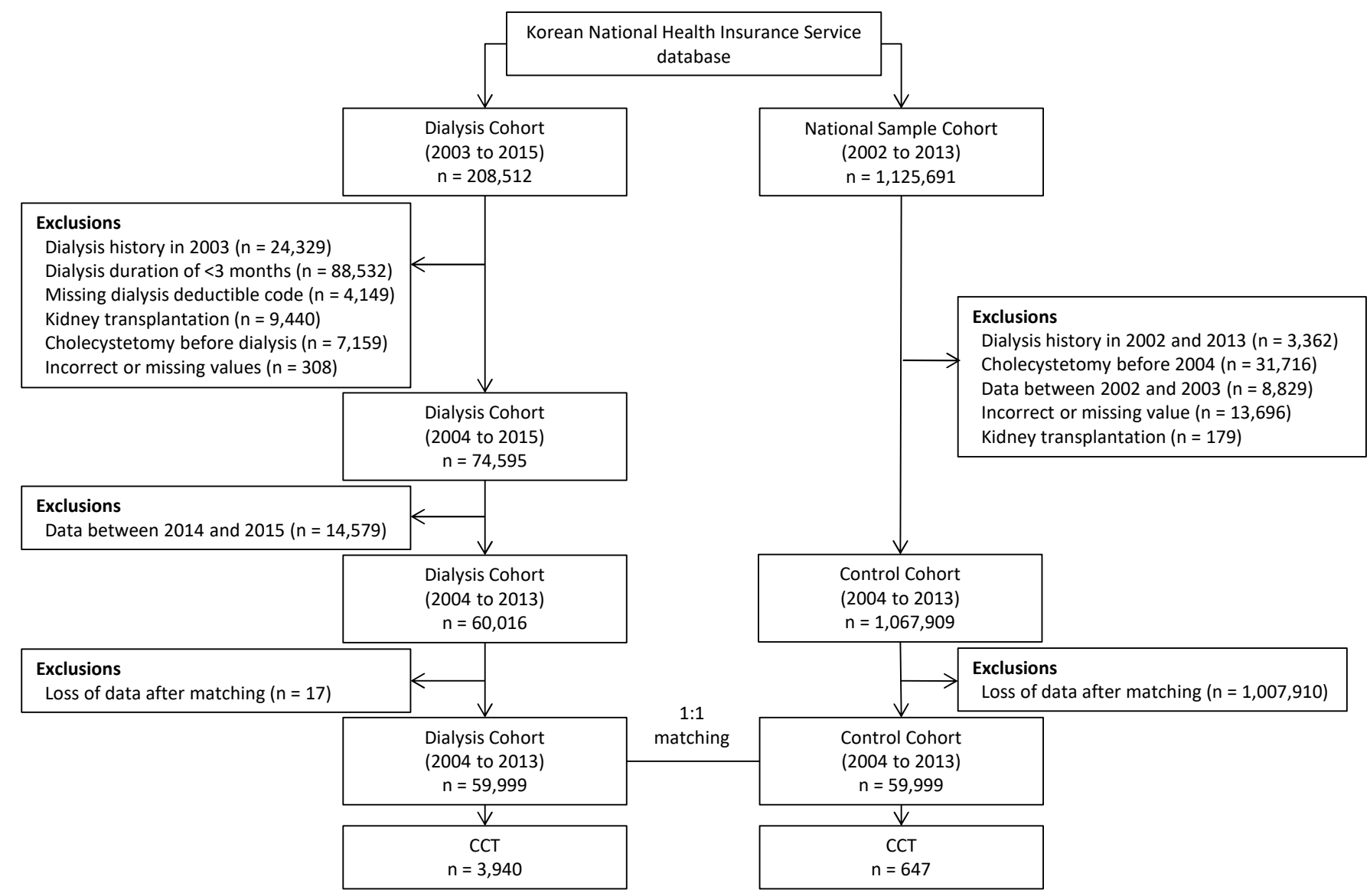

Figure 1. Patient and control enrollment flowchart showing the selection from the database. We evaluated 59,999 patients and compared them with 59,999 non-dialysis subjects selected from the National Sample Cohort of 1,125,691 Koreans via propensity score matching.

CCT, acute cholecystitis patients who underwent cholecystectomy.

defined as follows; admission to an acute care hospital with diagnostic codes of acute or other cholecystitis regardless of calculus (ICD-10 K80, K81, K82) with confirmed cholecystitis by pathology after performing cholecystectomy (Q7380) [12]. We excluded patients who were diagnosed with cholecystitis and/or cholecystectomy before the start of dialysis. The factors associated with the incidence of acute cholecystitis, such as age, sex, income level, Charlson comorbidity index (CCI), and comorbidities, were used as independent variables. The comorbidities for covariates, such as diabetes mellitus, hypertension, hyperlipidemia, connective tissue disease, myocardial infarction, heart failure, peripheral vascular disease, severe liver disease, dementia, and atrial fibrillation, were selected based on a previous Taiwanese nationwide study [13,14] (Supplementary Material, available online). Income level was categorized into three groups after it was scored on a scale of 0 to 10 .

\section{Propensity score matching}

We included patients who began dialysis before their diagnosis of acute cholecystitis based on the visit date. Dialysis cohort data between 2014 and 2015 were excluded because in the KNHIS-NSC database only data up to 2013 was available. The eligible patients, who started dialysis between 2004 and 2013 (dialysis cohort), were identified after excluding potentially preexisting cases of dialysis or acute cholecystitis. We identified individuals without ESRD from the KNHIS-NSC database, who were propensity scorematched to an equal number of ESRD cases. Propensity score matching using the nearest neighbor method was performed to identify similar individuals in the dialysis and 
control cohorts [15]. Logistic regression was used to obtain propensity scores for each patient based on their age, sex, income level, and CCI as well as comorbidities. Individuals in both cohorts were randomly ordered and matched 1:1 using the nearest neighbor method (Fig. 1).

\section{Statistical analysis}

Proportional differences in independent variables between the dialysis and control cohorts were analyzed using the Wald chi-square test. The acute cholecystitis incidence rate was expressed as the number of newly diagnosed acute cholecystitis cases per 10,000 person-years from the database. The incidence rate ratio (IRR) of dialysis cohorts, relative to the controls, was calculated with a $95 \%$ confidence interval (CI). The cumulative incidence of acute cholecystitis was calculated by using the Kaplan-Meier method and analyzed by the log-rank test. We applied the multivariate Cox proportional hazards model to all independent variables after combining the two cohorts to determine the dialysis-associated risk of developing acute cholecystitis, which was described as hazard ratio (HR). The follow-up period started on the first date of dialysis for the cases and on randomly selected visit dates for the controls, which occurred in years that matched the start of dialysis for the cases. The follow-up period ended on the first date of acute cholecystitis diagnosis or the last follow-up date. Analyses were performed using the statistical package SAS version 9.4 (SAS Institute, Cary, NC, USA) and R version 3.4.3 (R Foundation for Statistical Computing, Vienna, Austria). A statistical significance level of 0.05 was established.

\section{Ethics statement}

The retrospective protocol of this study was performed in accordance with the Declaration of Helsinki and approved by the Institutional Review Board (IRB) of Chungbuk National University Hospital in Cheongju, Republic of Korea (No. 2016-11-009). We used encrypted national insurance data. The IRB exempted our study from informed consent. All encrypted patients' records from the KNHIS were anonymized to ensure patient confidentiality.

\section{Results}

\section{Baseline characteristics of the dialysis and control cohort}

A total of 208,512 patients who were newly diagnosed with ESRD were selected from the KNHIS database. Patients who had undergone dialysis before $2003(24,329)$, with a dialysis duration of less than 3 months $(88,532)$, without a dialysis deductible code $(4,149)$, who had incorrect or missing value $(308)$, and who had kidney transplantation $(9,440)$ were excluded. Patients who underwent cholecystectomy before the initiation of dialysis $(7,159)$ were also excluded. A total of 59,999 patients were included in the patient arm, and 59,999 patients from the NSC of the 1,125,691 Korean population were included in the propensity score-matched group (Fig. 1).

The baseline characteristics and comorbidities between the dialysis and control cohorts are summarized in Table 1 . In the dialysis cohort, 34,772 patients $(58.0 \%)$ were men, and the mean duration of dialysis was $2.76 \pm 2.76$ years. The dialysis patients commonly commenced at 50 to 79 years of age $(43,346,72.0 \%)$ in comparison with a similar number of patients in the matched control cohort. In total, 54,103 patients underwent hemodialysis $(90.2 \%)$, whereas 5,896 underwent peritoneal dialysis (9.8\%).

\section{Comparison of acute cholecystitis in the dialysis and con- trol cohort}

Among the 59,999 dialysis patients and 59,999 controls, 3,940 dialysis patients (6.6\%) developed acute cholecystitis, and 647 controls (1.1\%) developed cholecystitis (Table 2). The overall incidence of acute cholecystitis was remarkably higher in the dialysis patients than controls (IRR, 8.04; 95\% CI, 7.40-8.76). The cumulative incidence of acute cholecystitis was significantly higher in dialysis patients than controls $(\mathrm{p}<0.001)$, the result is illustrated in Fig. 2. In the subgroup analysis, the incidence of acute cholecystitis was similarly elevated in the dialysis group (Table 2). Because the variables were different between dialysis and the control group, we analyzed the HR by multivariate analysis. Multivariate Cox proportional hazards analysis revealed that dialysis was a significant risk factor for acute cholecystitis with an HR of 8.94 (95\% CI, 8.19-9.76) (Table 3).

In the subgroup of dialysis modality, acute cholecystitis 
Table 1. Baseline characteristics of the dialysis patients and controls

\begin{tabular}{|c|c|c|}
\hline Characteristic & Dialysis & Control \\
\hline No. of patients & 59,999 & 59,999 \\
\hline \multicolumn{3}{|l|}{ Sex } \\
\hline Male & $34,772(58.0)$ & $31,838(53.1)$ \\
\hline Female & $25,227(42.0)$ & $28,161(46.9)$ \\
\hline \multicolumn{3}{|l|}{ Age (yr) } \\
\hline $0-29$ & $1,083(1.8)$ & $874(1.5)$ \\
\hline $30-39$ & $3,408(5.7)$ & $2,630(4.4)$ \\
\hline $40-49$ & $8,849(14.7)$ & $7,225(12.0)$ \\
\hline $50-59$ & $14,086(23.5)$ & $13,090(21.8)$ \\
\hline $60-69$ & $16,317(27.2)$ & $16,943(28.2)$ \\
\hline $70-79$ & $12,943(21.6)$ & $14,815(24.7)$ \\
\hline$\geq 80$ & $3,313(5.5)$ & 4,422 (7.4) \\
\hline \multicolumn{3}{|l|}{ Income level } \\
\hline Low & 23,301 (38.8) & $17,210(28.7)$ \\
\hline Middle & $18,446(30.7)$ & $21,472(35.8)$ \\
\hline High & $18,252(30.4)$ & $21,317(35.5)$ \\
\hline \multicolumn{3}{|l|}{ CCl score } \\
\hline$\leq 1$ & $6,400(10.7)$ & $5,326(8.9)$ \\
\hline 2 & 6,332 (10.6) & $5,611(9.4)$ \\
\hline$\geq 3$ & $47,267(78.8)$ & $49,062(81.8)$ \\
\hline \multicolumn{3}{|l|}{ Comorbidity } \\
\hline Diabetes mellitus & $43,591(72.7)$ & $43,062(71.8)$ \\
\hline Hypertension & $53,253(88.8)$ & $55,006(91.7)$ \\
\hline Hyperlipidemia & $40,773(68.0)$ & $42,083(70.1)$ \\
\hline Connective tissue disease & $5,304(8.8)$ & $10,172(17.0)$ \\
\hline Myocardial infarction & 6,877 (11.5) & $6,211(10.4)$ \\
\hline Heart failure & $19,470(32.5)$ & $15,240(25.4)$ \\
\hline Peripheral vascular disease & 18,687 (31.1) & $27,393(45.7)$ \\
\hline Severe liver disease & 2,016 (3.4) & $2,424(4.0)$ \\
\hline Dementia & $3,495(5.8)$ & $9,591(16.0)$ \\
\hline Atrial fibrillation & $3,637(6.1)$ & $4,685(7.8)$ \\
\hline \multicolumn{3}{|l|}{ Dialysis modality } \\
\hline Hemodialysis & $54,103(90.0)$ & \\
\hline Peritoneal dialysis & $5,896(10.0)$ & \\
\hline
\end{tabular}

Values are presented as number of patients (\%). $\mathrm{CCl}$, Charlson comorbidity index.

occurred in 3,558 of 54,103 hemodialysis patients (6.6\%) and in 382 of 5,896 peritoneal dialysis patients (6.5\%). After variables were adjusted, hemodialysis patients were at a lower risk of acute cholecystitis than peritoneal dialysis patients (adjusted HRs, 0.84; 95\% CI, 0.76-0.94; $\mathrm{p}<0.01$ ), and a significant difference was observed (Table 4, Fig. 3).

\section{Discussion}

This nationwide cohort study found that patients with ESRD undergoing dialysis were associated with an 8.94fold higher risk of acute cholecystitis than the matched control group. This is the largest cohort study to investigate the incidence and risk factors of acute cholecystitis after the initiation of dialysis for ESRD in the Korean population. A recent Taiwanese nationwide cohort study that consisted of 54,065 patients with new-onset ESRD reported that the incidence of acute cholecystitis was 5.8/1,000 patient-years. In addition, patients with ESRD were associated with a 6.83fold higher risk of developing acute cholecystitis [13].

Acute cholecystitis is commonly associated with inflammation caused by prolonged obstruction of the cystic duct with gallstones [16]. Even though gallstones are the most important factor in the pathogenesis of acute cholecystitis, there are also many other investigated factors for developing gallstones $[17,18]$. Although many studies have investigated the relationship between gallstones and ESRD, it remains to be clarified whether gallstones are more common in patients with ESRD [16-18]. Some studies report that the incidence of gallstones in patients on hemodialysis was not different from that in controls [19-24], whereas others have reported a higher incidence of gallstones in patients on hemodialysis than in the control group [25-30]. In this study, both hemodialysis and peritoneal dialysis were associated with an increased risk of developing acute cholecystitis. In terms of dialysis modality, hemodialysis patients were at a lower risk of acute cholecystitis than peritoneal dialysis patients.

In patients on hemodialysis, hemodynamic fluctuations cause hypoperfusion to organs. The resulting frequent mesenteric ischemia leads to disruption of the gut mucosal structure with increased gut permeability, and chronic malnutrition causing a higher incidence of peptic ulcer disease. Dialysis patients with poor nutrition have a higher incidence of peptic ulcer disease [31]. This could occur in the gallbladder. The ischemia and reperfusion injury leads to epithelial damage of the gallbladder. Additionally, increased circulating uremic toxin levels in hemodialysis patients cause systemic inflammation. Moreover, increased leukocyte margination and focal lymphatic dilation with interstitial edema are associated with local microvascular occlusion [32-34]. In peritoneal dialysis patients, acute 
Table 2. The incidence of acute cholecystitis according to baseline characteristics among dialysis patients and controls

\begin{tabular}{|c|c|c|c|c|c|c|c|}
\hline \multirow{2}{*}{ Characteristic } & \multicolumn{3}{|c|}{ Dialysis $(n=59,999)$} & \multicolumn{3}{|c|}{ Control $(n=59,999)$} & \multirow{2}{*}{$\operatorname{IRR}(95 \% \mathrm{Cl})$} \\
\hline & No. (\%) & PY & IR/1,000 PY & No. (\%) & PY & IR & \\
\hline Case & $3,940(6.6)$ & 205,456 & 19 & 647 (1.1) & 271,419 & 2 & $8.04(7.40-8.76)$ \\
\hline \multicolumn{8}{|l|}{ Sex } \\
\hline Male & $2,298(3.8)$ & 117,146 & 20 & $370(0.6)$ & 140,807 & 3 & 7.47 (6.69-8.35) \\
\hline Female & $1,642(2.7)$ & 88,310 & 19 & $277(0.5)$ & 130,612 & 2 & 8.77 (7.71-9.99) \\
\hline \multicolumn{8}{|l|}{ Age (yr) } \\
\hline $0-29$ & $36(0.1)$ & 4,979 & 7 & $4(0.0)$ & 4,775 & 1 & $8.63(3.09-33.38)$ \\
\hline $30-39$ & $182(0.3)$ & 15,882 & 11 & $28(0.0)$ & 13,607 & 2 & $5.57(3.73-8.61)$ \\
\hline $40-49$ & $569(0.9)$ & 38,692 & 15 & $61(0.1)$ & 36,188 & 2 & $8.72(6.69-11.56)$ \\
\hline $50-59$ & 955 (1.6) & 53,090 & 18 & $154(0.3)$ & 64,101 & 2 & 7.49 (6.31-8.94) \\
\hline $60-69$ & 1,165 (1.9) & 54,258 & 21 & $226(0.4)$ & 81,384 & 3 & $7.73(6.70-8.96)$ \\
\hline $70-79$ & $846(1.4)$ & 32,456 & 26 & $157(0.3)$ & 58,538 & 3 & $9.72(8.19-11.60)$ \\
\hline$\geq 80$ & $187(0.3)$ & 6,100 & 31 & $17(0.0)$ & 12,826 & 1 & $23.13(14.06-40.55)$ \\
\hline \multicolumn{8}{|l|}{ Income level } \\
\hline Low & $1,745(2.9)$ & 91,795 & 19 & $142(0.2)$ & 82,767 & 2 & $11.08(9.33-13.24)$ \\
\hline Middle & $1,067(1.8)$ & 59,791 & 18 & $252(0.4)$ & 95,682 & 3 & $6.78(5.90-7.80)$ \\
\hline High & $1,128(1.9)$ & 53,870 & 21 & $253(0.4)$ & 92,969 & 3 & 7.69 (6.71-8.85) \\
\hline \multicolumn{8}{|l|}{ CCl score } \\
\hline$\leq 1$ & $508(0.8)$ & 35,361 & 14 & $41(0.1)$ & 34,147 & 1 & $11.96(8.70-16.88)$ \\
\hline 2 & $447(0.7)$ & 27,335 & 16 & $64(0.1)$ & 29,080 & 2 & 7.43 (5.71-9.81) \\
\hline$\geq 3$ & $2,985(5.0)$ & 142,760 & 21 & $542(0.9)$ & 208,192 & 3 & $8.03(7.33-8.82)$ \\
\hline \multicolumn{8}{|l|}{ Comorbidity } \\
\hline Diabetes mellitus & $2,670(4.5)$ & 129,602 & 21 & $498(0.8)$ & 182,565 & 3 & 7.55 (6.86-8.33) \\
\hline Hypertension & $3,310(5.5)$ & 167,101 & 20 & $607(1.0)$ & 238,249 & 3 & 7.77 (7.13-8.49) \\
\hline Hyperlipidemia & $2,430(4.1)$ & 118,317 & 21 & $477(0.8)$ & 178,739 & 3 & $7.70(6.97-8.51)$ \\
\hline Connective tissue disease & $313(0.5)$ & 14,118 & 22 & $121(0.2)$ & 49,788 & 2 & $9.12(7.37-11.35)$ \\
\hline Myocardial infarction & $476(0.8)$ & 18,478 & 26 & $105(0.2)$ & 28,073 & 4 & 6.89 (5.56-8.59) \\
\hline Heart failure & $1,252(2.1)$ & 52,671 & 24 & $198(0.3)$ & 67,532 & 3 & $8.11(6.97-9.47)$ \\
\hline Peripheral vascular disease & $1,067(1.8)$ & 46,129 & 23 & $314(0.5)$ & 124,894 & 3 & $9.20(8.10-10.47)$ \\
\hline Severe liver disease & $163(0.3)$ & 5,161 & 32 & $54(0.1)$ & 9,901 & 5 & $5.79(4.23-8.03)$ \\
\hline Dementia & $184(0.3)$ & 6,255 & 29 & $98(0.2)$ & 40,233 & 2 & $12.08(9.40-15.59)$ \\
\hline Atrial fibrillation & $227(0.4)$ & 9,075 & 25 & $76(0.1)$ & 20,475 & 4 & $6.74(5.18-8.86)$ \\
\hline
\end{tabular}

$\mathrm{CCl}$, Charlson comorbidity index; $\mathrm{Cl}$, confidence interval; IR, incidence rate; IRR, incidence rate ratio; PY, person-years.

cholecystitis is caused by chronic active inflammation of the peritoneum and endotoxemia [35,36]. We hypothesize that chronic inflammation of the gallbladder and decreased gallbladder motility due to uremia caused the increased incidence of cholecystitis.

In the management of acute cholecystitis, laparoscopic cholecystectomy is recommended as a first-line treatment in the general population [37]. However, previous studies on the outcomes of patients with ESRD undergoing cholecystectomy have reported that ESRD is an independent risk factor for postoperative morbidity $[38,39]$. Although patients on dialysis are at risk of postoperative complications, laparoscopic cholecystectomy is recommended as a first-line treatment for acute cholecystitis even in patients undergoing peritoneal dialysis [40-44]. In severe acute cholecystitis, operative management increased morbidity and mortality. Chung et al. [45] reported that emergent laparoscopic cholecystectomy for acute cholecystitis in patients with ESRD was an independent risk factor for mortality. Therefore, patients with acute cholecystitis must be treated before exacerbation of the inflammation. To avoid operative complications, Gunay et al. [46] suggested percutaneous 


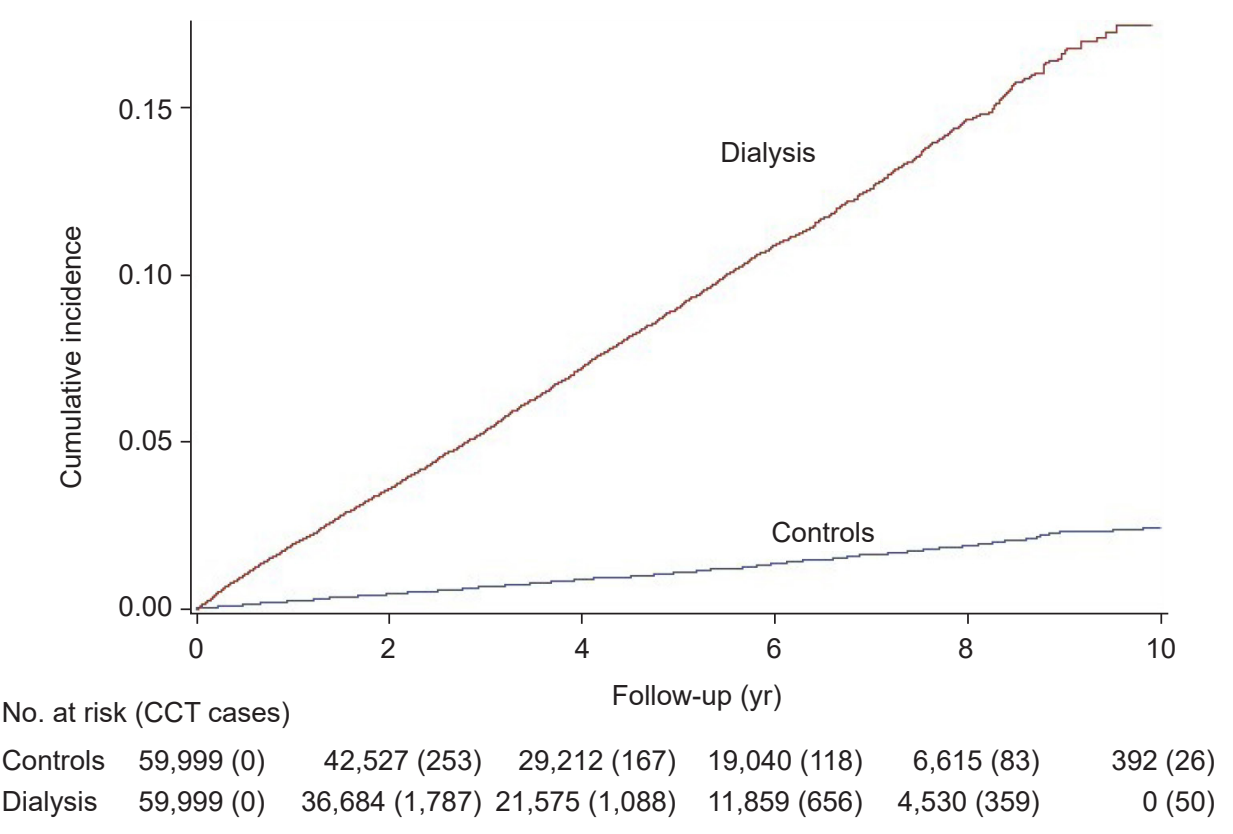

Figure 2. Cumulative incidence of acute cholecystitis in patients with end-stage renal disease and controls. The cumulative incidence of acute cholecystitis was significantly higher in dialysis patients $(p<0.001)$.

CCT, acute cholecystitis patients who underwent cholecystectomy.

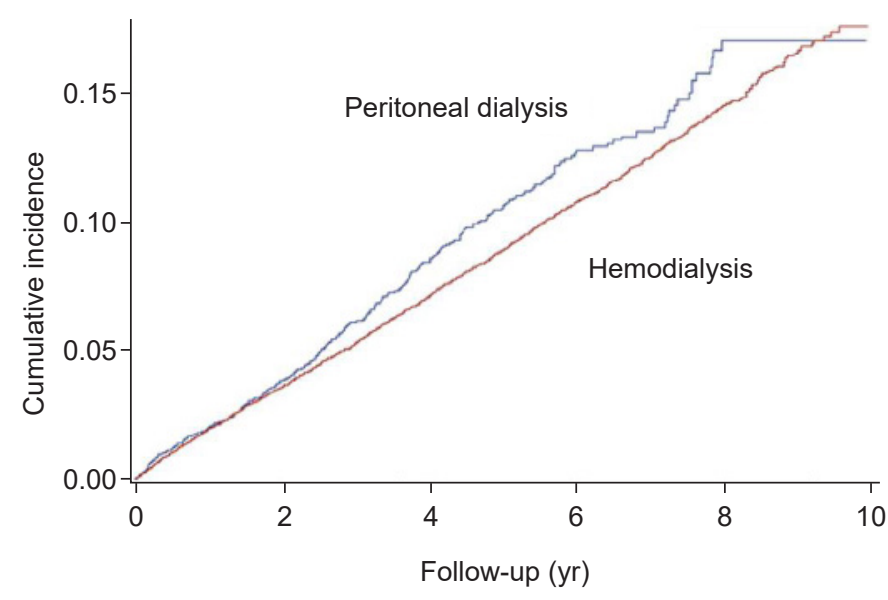

Figure 3. Cumulative incidence of acute cholecystitis in patients with end-stage renal disease by dialysis modality. The cumulative incidence of acute cholecystitis in peritoneal dialysis patients was higher than in hemodialysis patients $(p<0.01)$.

cholecystostomy as a bridging method or palliative option to treat acute cholecystitis in some selected chronic hemodialysis patients.

There were limitations to the current study. First, we were unable to demonstrate the cause of acute cholecystitis. As we were unable to differentiate between the subtypes of acute cholecystitis (i.e., emphysematous cholecystitis, acalculous cholecystitis) in our dataset, we could not find a relationship between ESRD and gallstone disease. Second, it is possible that a case diagnosed with cholecystitis, but not having surgery or having undergone gallbladder drainage, may have been excluded from both groups. Since 2003, the code for cholecystectomy can be confirmed in the data, so patients in the dialysis group and the control group belong to the definition of cholecystitis in this study, "Cholecystectomy with cholecystitis and histologically confirmed" were identified and excluded, and many dialysis patients underwent percutaneous cholecystostomy due to poor medical conditions with a high rate of readmission [46]. Because we used a cholecystectomy code for specifying acute cholecystitis, we did not include a cholecystostomy code at initiation, which might be an important limitation in our study. Third, we used a general Cox model to control the selected covariates. After the 'proportional hazards' assumption is confirmed, stratified Cox analysis should be performed rather than general Cox analysis for propensity score matching data. However, in the matching, the HR of the general Cox analysis is smaller than that of the stratified Cox analysis, and the HR is underestimated. Therefore, the result does not change even if the analysis method is dif- 
Table 3. Univariate and multivariate analysis of risk factors for acute cholecystitis

\begin{tabular}{|c|c|c|}
\hline Variable & $\begin{array}{l}\text { Crude HR } \\
(95 \% \mathrm{Cl})\end{array}$ & $\begin{array}{c}\text { Adjusted } \mathrm{HR}^{\mathrm{a}} \\
(95 \% \mathrm{Cl})\end{array}$ \\
\hline \multicolumn{3}{|l|}{ Dialysis } \\
\hline No & 1.00 & 1.00 \\
\hline Yes & $8.10(7.46-8.81)$ & $8.94(8.19-9.76)$ \\
\hline \multicolumn{3}{|l|}{ Sex } \\
\hline Male & 1.00 & 1.00 \\
\hline Female & $0.85(0.8-0.9)$ & $0.90(0.84-0.95)$ \\
\hline \multicolumn{3}{|l|}{ Age (yr) } \\
\hline $0-29$ & 1.00 & 1.00 \\
\hline $30-39$ & $1.74(1.24-2.43)$ & $1.64(1.17-2.29)$ \\
\hline $40-49$ & $2.05(1.49-2.82)$ & $1.94(1.41-2.67)$ \\
\hline $50-59$ & $2.30(1.68-3.15)$ & $2.36(1.72-3.24)$ \\
\hline $60-69$ & $2.49(1.82-3.41)$ & $2.80(2.04-3.84)$ \\
\hline $70-79$ & $2.66(1.94-3.65)$ & $3.26(2.37-4.49)$ \\
\hline$\geq 80$ & $2.57(1.83-3.61)$ & $3.38(2.40-4.76)$ \\
\hline \multicolumn{3}{|l|}{ Income level } \\
\hline Low & 1.00 & 1.00 \\
\hline Middle & $0.78(0.73-0.84)$ & $0.87(0.81-0.94)$ \\
\hline High & $0.87(0.81-0.93)$ & $0.90(0.84-0.97)$ \\
\hline \multicolumn{3}{|l|}{$\mathrm{CCl}$ score } \\
\hline$\leq 1$ & 1.00 & 1.00 \\
\hline 2 & $1.15(1.02-1.29)$ & $1.20(1.06-1.36)$ \\
\hline$\geq 3$ & $1.26(1.15-1.38)$ & $1.30(1.15-1.47)$ \\
\hline \multicolumn{3}{|l|}{ Comorbidity } \\
\hline Diabetes mellitus & $1.17(1.10-1.24)$ & $1.00(0.92-1.08)$ \\
\hline Hypertension & $1.02(0.94-1.11)$ & $0.89(0.80-1.00)$ \\
\hline Hyperlipidemia & $1.04(0.98-1.10)$ & $1.06(0.99-1.14)$ \\
\hline Connective tissue disease & $0.68(0.61-0.75)$ & $1.02(0.92-1.12)$ \\
\hline Myocardial infarction & $1.34(1.23-1.46)$ & $1.19(1.09-1.31)$ \\
\hline Heart failure & $1.36(1.28-1.45)$ & $1.16(1.08-1.24)$ \\
\hline Peripheral vascular disease & $0.77(0.72-0.82)$ & $1.08(1.01-1.16)$ \\
\hline Severe liver disease & $1.52(1.32-1.74)$ & $1.66(1.45-1.90)$ \\
\hline Dementia & $0.60(0.54-0.68)$ & $1.04(0.92-1.18)$ \\
\hline Atrial fibrillation & $1.07(0.95-1.20)$ & $1.12(1.00-1.27)$ \\
\hline
\end{tabular}

$\mathrm{Cl}$, confidence interval; $\mathrm{CCl}$, Charlson comorbidity index; $\mathrm{HR}$, hazard ratio.

${ }^{a}$ Adjusted for sex, age, income level, diabetes mellitus, hypertension, hyperlipidemia, connective tissue disease, myocardial infarction, heart failure, peripheral vascular disease, severe liver disease, dementia, atrial fibrillation, and $\mathrm{CCl}$. ferent. However, because differences due to the size of the sample cannot be completely excluded, repeated studies are needed for validation. In addition, we could not evaluate individual data such as smoking history, body mass index, and laboratory values, which can contribute to acute cholecystitis with gallstones. Further randomized controlled studies would unveil the precise mechanism of the clinical course and mortality associated with acute cholecystitis in dialysis patients.

In conclusion, we found that patients undergoing dialysis have a higher incidence and risk of acute cholecystitis compared to the general population. As acute cholecystitis in a patient with dialysis is associated with high mobility and mortality rates, the possibility of developing a gallbladder disorder in patients with gastrointestinal problems should be considered in the dialysis clinic. Further investigations are required to explore the development of acute cholecystitis and gallstones in patients with ESRD.

\section{Conflicts of interest}

All authors have no conflicts of interest to declare.

\section{Funding}

This work was supported by a research grant from the Chungbuk National University in 2020.

\section{Authors' contributions}

\section{Conceptualization: HC, SKK, JHH, GK}

Data curation: MK

Formal analysis: HC, SKK, GK, MK

Funding acquisition: $\mathrm{JHH}$

Writing - original draft: HC, SKK, JHH, JSL, GK

Writing-review \& editing: HC, SKK, JHH

All authors read and approved the final manuscript.

Table 4. Hazard ratio (HR) and $95 \%$ confidence interval $(\mathrm{Cl})$ according to the type of dialysis

\begin{tabular}{lcccc}
\hline Type of dialysis & No. of all cases & No. of cholecystitis cases (\%) & Crude HR $(95 \% \mathrm{Cl})$ & Adjusted HR $(95 \% \mathrm{Cl})$ \\
\hline Peritoneal dialysis & 5,896 & $382(6.5)$ & 1.00 & 1.00 \\
Hemodialysis & 54,103 & $3,558(6.6)$ & $0.88(0.79-0.97)^{*}$ & $0.84(0.76-0.94)^{* *}$ \\
\hline
\end{tabular}

${ }^{a}$ Adjusted for sex, age, income level, diabetes mellitus, hypertension, hyperlipidemia, connective tissue disease, myocardial infarction, heart failure, peripheral vascular disease, severe liver disease, dementia, atrial fibrillation, and Charlson comorbidity index.

$* p<0.05, * * p<0.01$. 


\section{ORCID}

Hanlim Choi, https://orcid.org/0000-0003-0130-3292

Soon Kil Kwon, https://orcid.org/0000-0001-9287-4490

Joung-Ho Han, https://orcid.org/0000-0003-4469-9215

Jun Su Lee, https://orcid.org/0000-0003-0470-7583

Gilwon Kang, https://orcid.org/0000-0003-0222-1870

Minseok Kang, https://orcid.org/0000-0001-7049-821X

\section{References}

1. Strasberg SM. Clinical practice: acute calculous cholecystitis. $N$ Engl J Med 2008;358:2804-2811.

2. Kimura Y, Takada T, Kawarada Y, et al. Definitions, pathophysiology, and epidemiology of acute cholangitis and cholecystitis: Tokyo Guidelines. J Hepatobiliary Pancreat Surg 2007;14:15-26.

3. Yokoe M, Takada T, Hwang TL, et al. Descriptive review of acute cholecystitis: Japan-Taiwan collaborative epidemiological study. J Hepatobiliary Pancreat Sci 2017;24:319-328.

4. Kim S, Lim CS, Han DC, et al. The prevalence of chronic kidney disease (CKD) and the associated factors to CKD in urban Korea: a population-based cross-sectional epidemiologic study. $J$ Korean Med Sci 2009;24(Suppl 1):S11-S21.

5. Foster BJ, Mitsnefes MM, Dahhou M, Zhang X, Laskin BL. Changes in excess mortality from end stage renal disease in the United States from 1995 to 2013. Clin J Am Soc Nephrol 2018;13: 91-99.

6. Johansen KL. Life Expectancy gains for patients with ESRD. Clin J Am Soc Nephrol 2018;13:11-12.

7. Cano AE, Neil AK, Kang JY, et al. Gastrointestinal symptoms in patients with end-stage renal disease undergoing treatment by hemodialysis or peritoneal dialysis. Am J Gastroenterol 2007; 102:1990-1997.

8. Trimingham C, McDonald S, Dansie K, et al. Bowel health in chronic kidney disease: patient perceptions differ from clinical definitions. J Ren Care 2018;44:65-72.

9. Min J, Kwon SK, Jeong HW, et al. End-stage renal disease and risk of active tuberculosis: a nationwide population-based cohort study. J Korean Med Sci 2018;33:e341.

10. Kwon SK, Han JH, Kim HY, et al. The incidences and characteristics of various cancers in patients on dialysis: a Korean nationwide study. J Korean Med Sci 2019;34:e176.

11. Lee J, Lee JS, Park SH, Shin SA, Kim K. Cohort profile: the National Health Insurance Service-National Sample Cohort (NHISNSC), South Korea. Int J Epidemiol 2017;46:e15.
12. Riall TS, Zhang D, Townsend CM Jr, Kuo YF, Goodwin JS. Failure to perform cholecystectomy for acute cholecystitis in elderly patients is associated with increased morbidity, mortality, and cost. J Am Coll Surg 2010;210:668-679.

13. Chen YT, Ou SM, Chao PW, et al. Acute cholecystitis in end-stage renal disease patients: a nation-wide longitudinal study. Dig Liver Dis 2013;45:142-146.

14. Tai SY, Chien CY, Wu DC, et al. Risk of dementia from proton pump inhibitor use in Asian population: a nationwide cohort study in Taiwan. PLoS One 2017;12:e0171006.

15. Austin PC. A comparison of 12 algorithms for matching on the propensity score. Stat Med 2014;33:1057-1069.

16. Roslyn JJ, DenBesten L, Thompson JE Jr, Silverman BF. Roles of lithogenic bile and cystic duct occlusion in the pathogenesis of acute cholecystitis. Am J Surg 1980;140:126-130.

17. Novacek G. Gender and gallstone disease. Wien Med Wochenschr 2006;156:527-533.

18. Reshetnyak VI. Concept of the pathogenesis and treatment of cholelithiasis. World J Hepatol 2012;4:18-34.

19. Altiparmak MR, Pamuk ON, Pamuk GE, et al. Incidence of gallstones in chronic renal failure patients undergoing hemodialysis: experience of a center in Turkey. Am J Gastroenterol 2003; 98:813-820.

20. Gladziwa U, Wagner S, Riehl J, Sieberth HG. Prevalence of cholelithiasis in haemodialysis patients. Nephrol Dial Transplant 1993;8:1397-1400.

21. Paydas S, Seyrek N, Gorkel Y, Sagliker Y. Prevalence of cholelithiasis in patients with end-stage renal disease. Nephron 1996;72: 115-116.

22. Korzets Z, Golan E, Ben-Chitrit S, et al. Prevalence of cholelithiasis in non-diabetic haemodialysis and continuous ambulatory peritoneal dialysis patients. Nephron 1998;78:44-47.

23. Dumlu S, Bali M, Yilmaz M, et al. Prevalence of gallstone disease in hemodialysis patients. Nephron 1998;78:347-348.

24. Hojs R. Cholecystolithiasis in patients with end-stage renal disease treated with haemodialysis: a study of prevalence. Am J Nephrol 1995;15:15-17.

25. Badalamenti S, DeFazio C, Castelnovo C, et al. High prevalence of silent gallstone disease in dialysis patients. Nephron 1994; 66:225-227.

26. Hahm JS, Lee HL, Park JY, Eun CS, Han DS, Choi HS. Prevalence of gallstone disease in patients with end-stage renal disease treated with hemodialysis in Korea. Hepatogastroenterology 2003;50:1792-1795.

27. Li Vecchi M, Soresi M, Cusimano R, et al. Prevalence of biliary 
lithiasis in a Sicilian population of chronic renal failure patients. Nephrol Dial Transplant 2003;18:2321-2324.

28. Kazama JJ, Kazama S, Koda R, Yamamoto S, Narita I, Gejyo F. The risk of gallbladder stone formation is increased in patients with predialysis chronic kidney disease but not those undergoing chronic hemodialysis therapy. Nephron Clin Pract 2009;111:c167-c172.

29. Elsadek HM, Qasem AA, Farag SE, AlSowy AM, Ebouda FM, Alghamdi FS. Gallbladder dysfunction and gallstone prevalence in patients with chronic kidney disease: is there a difference between predialysis and hemodialysis patients?: a multi-center study. Int J 2014;2:842-848.

30. Lai SW, Liao KF, Lai HC, Chou CY, Cheng KC, Lai YM. The prevalence of gallbladder stones is higher among patients with chronic kidney disease in Taiwan. Medicine (Baltimore) 2009;88:4651.

31. Kim M, Kim CS, Bae EH, Ma SK, Kim SW. Risk factors for peptic ulcer disease in patients with end-stage renal disease receiving dialysis. Kidney Res Clin Pract 2019;38:81-89.

32. Kaminski DL, Feinstein WK, Deshpande YG. The production of experimental cholecystitis by endotoxin. Prostaglandins 1994;47:233-245.

33. Tabata M. Experimental study of the pathogenesis of acute acalculous cholecystitis: role of autonomic denervation. J Gastroenterol 1994;29:320-331.

34. Taoka H. Experimental study on the pathogenesis of acute acalculous cholecystitis, with special reference to the roles of microcirculatory disturbances, free radicals and membrane-bound phospholipase A2. Gastroenterol Jpn 1991;26:633-644.

35. Cho Y, Hawley CM, Johnson DW. Clinical causes of inflammation in peritoneal dialysis patients. Int J Nephrol 2014;2014:909373.

36. Zoccali C, Tripepi G, Mallamaci F. Dissecting inflammation in ESRD: do cytokines and C-reactive protein have a complementary prognostic value for mortality in dialysis patients? J Am Soc Nephrol 2006;17(12 Suppl 3):S169-S173.

37. Wakabayashi G, Iwashita Y, Hibi T, et al. Tokyo Guidelines 2018: surgical management of acute cholecystitis: safe steps in laparoscopic cholecystectomy for acute cholecystitis (with videos). J Hepatobiliary Pancreat Sci 2018;25:73-86.

38. Tam SF, Au JT, Sako W, Alfonso AE, Sugiyama G. How sick are dialysis patients undergoing cholecystectomy?: analysis of 92,672 patients from the American College of Surgeons National Surgical Quality Improvement Program database. Am J Surg 2015; 210:864-870.

39. Rao A, Polanco A, Chin E, Divino CM, Qiu S, Nguyen SQ. Safety of elective laparoscopic cholecystectomy in patients on dialysis: an analysis of the ACS NSQIP database. Surg Endosc 2014;28: 2208-2212.

40. Magnuson TH, Bender JS, Campbell KA, Ratner LE. Cholecystectomy in the peritoneal dialysis patient: unique advantages to the laparoscopic approach. Surg Endosc 1995;9:908-909.

41. Yeh CN, Chen MF, Jan YY. Laparoscopic cholecystectomy for 58 end stage renal disease patients. Surg Endosc 2005;19:915-918.

42. Ekici Y, Tezcaner T, Aydoğan C, Karakayalı FY, Moray G. Outcomes of laparoscopic cholecystectomy in patients with endstage renal disease. Int J Clin Med 2014;5:1300-1305.

43. Ekici Y, Karakayali F, Yagmurdur MC, Moray G, Karakayal H, Haberal M. Laparoscopic cholecystectomy in patients undergoing continuous ambulatory peritoneal dialysis: a case-control study. Surg Laparosc Endosc Percutan Tech 2009;19:101-105.

44. Mari G, Scanziani R, Auricchio S, Crippa J, Maggioni D. Laparoscopic surgery in patients on peritoneal dialysis: a review of the literature. Surg Innov 2017;24:397-401.

45. Chung PJ, Smith MC, Roudnitsky V, Lee JS, Alfonso AE, Sugiyama G. A calculated risk: performing laparoscopic cholecystectomy for acute cholecystitis on patients with end stage renal disease. Am Surg 2018;84:963-970.

46. Gunay Y, Bircan HY, Emek E, Cevik H, Altaca G, Moray G. The management of acute cholecystitis in chronic hemodialysis patients: percutaneous cholecystostomy versus cholecystectomy. J Gastrointest Surg 2013;17:319-325. 